\title{
ERRATUM
}

\section{Correlation between two propulsion efficiency indices in front crawl Swimming}

\author{
Stefano Longo · Raffaele Scurati - Giovanni Michielon · Pietro Luigi Invernizzi
}

(C) Springer-Verlag 2009

\section{Erratum to: Sport Sci Health}

DOI 10.1007/s11332-008-0069-z

Unfortunately the article contains erroneous data. Please find the correct data here

\begin{abstract}
Page 65 , second column, line $8: \mathrm{R}=0.71$ should be replaced with $\mathrm{R}=0.69$

Page 65, second column, line 9: $\mathrm{R}=0.83$ should be replaced with $\mathrm{R}=0.73$
\end{abstract}

\section{Results}

Page 67, second column, line 19: $\mathrm{R}=0.71$ should be replaced with $\mathrm{R}=0.69$

Page 68, first column, line 1 : $R=0.83$ should be replaced with $\mathrm{R}=0.73$

\section{Discussion}

Page 71 , first column, line $14: \mathrm{R}=0.63$ should be replaced with $\mathrm{R}=0.73$

The online version of the original article can be found under doi: 10.1007/s11332-008-0069-z

S. Longo (西) · R. Scurati · G. Michielon · P.L. Invernizzi LaSA, Laboratory of Sports Analysis and Human Performance Faculty of Exercise Sciences

University of Milan

Milan, Italy

e-mail: stefano.longo@unimi.it 